Original Article

\title{
Should high-power posing be integrated in physical therapy?
}

\author{
Weiqing Ge, DPT, PhD ${ }^{1)^{*}}$, Teale K. Bennett, SPT ${ }^{1)}$, Jeremy C. Oller, SPT ${ }^{1)}$
}

1) Department of Physical Therapy, Youngstown State University: One University Plaza, Youngstown, $\mathrm{OH} 44555$, USA

\begin{abstract}
Purpose] Postural assessment and correction is a common approach in patient management to decrease symptoms and improve function for patients. The purpose of this study was to determine the effects of highpower posing on muscle strength and pain threshold. [Subjects and Methods] Thirty-one subjects, 16 females and 15 males, mean age 28.9 (SD 10.8) years old, were recruited through a convenience sampling on the university campus. The research design was a randomized controlled trial. In the experimental group, the subjects were instructed to stand in a high-power posture. In the control group, the subjects were instructed to stand in a low-power posture. Grip strength and pain threshold measurements were conducted before and after the postural intervention. [Results] The grip strength changed by $-3.4(-3.7,0.3) \%$ and $1.7(-3.6,5.3) \%$ for the experimental and control groups, respectively. The pain threshold changed by $0.6(-9.9,10.4) \%$ and $15.1(-9.3,24.4) \%$ for the experimental and control groups, respectively. However, both changes were not significant as all the $95 \%$ CIs included 0 . [Conclusions] The data did not show significant benefits of high-power posing in increasing grip strength and pain threshold compared to low-power posing.

Key words: Posture, Pain, Strength
\end{abstract}

(This article was submitted Nov. 9, 2016, and was accepted Jan. 10, 2017)

\section{INTRODUCTION}

Postural assessment and correction is a common approach in patient management to decrease symptoms and improve function for patients. It has been demonstrated that poor posture negatively impacts pain, range of motion, strength, proprioception, balance, and respiration: abnormal postures in the cervical, shoulder, and thoracic regions are associated with pain ${ }^{1)}$; a slouched posture can decrease shoulder range of motion and strength ${ }^{2}$; a slouched posture can also alter proprioceptive control, increase reposition error, and contribute to low back pain and injury ${ }^{3)}$; and a forward head posture decreases balance control in standing ${ }^{4)}$ and reduces vital capacity ${ }^{5}$. It should be noted that a recent systematic review concluded that thoracic spine posture may not be associated with shoulder pain ${ }^{6}$. Nevertheless, the focus of physical therapists on posture is often on the alignment of bony structures and/or balance between muscle groups.

High-power posing, an open, expansive, and dominant posture expressing high power, has gained attention around the world with over thirty-six million views of the renowned Technology, Entertainment and Design (TED) Talk "Your body language shapes who you are" by social psychologist Amy Cuddy ${ }^{7)}$. The number of views keeps growing every day. One minute of high-power posing has been found to increase testosterone level, decrease cortisol level, and increase feelings of power and tolerance for risk compared to low-power posing. (Low-power posing is a closed, contractive, and submissive posture expressing low power $\left.{ }^{8)}\right)$. Adopting a high-power pose for 5-6 minutes prior to a stressful job interview enhances nonverbal presence performance during the interview ${ }^{9)}$. High-power posing affects confirmatory information processing and increases confidence regarding the validity of decisions ${ }^{10}$. Interestingly, it was found that high-power posing could make

*Corresponding author. Weiqing Ge (E-mail: wge@ysu.edu)

(C)2017 The Society of Physical Therapy Science. Published by IPEC Inc.

This is an open-access article distributed under the terms of the Creative Commons Attribution Non-Commercial No Derivatives (by-nc-nd) License $<$ https://creativecommons.org/licenses/by-nc-nd/4.0/>. 
people more attractive and increase the chances of initial romantic success when seeking romantic relationship partners ${ }^{11)}$. Lastly, it should be noted that the impact of high-power posing depends on the individual's cultural orientation ${ }^{12)}$.

Since the introduction of gate control theory by Melzack and Wall in 1965 ${ }^{13}$, the assessment and management of pain has evolved significantly, and it is now commonly recognized that psychological factors can profoundly alter the perception of pain ${ }^{14)}$. It has been demonstrated that psychological factors play an important role in the development of persistent pain and disability ${ }^{15}$. Research literature has demonstrated the association between psychological factors and increased pain intensity in patients with a variety of conditions such as acute orthopaedic injury ${ }^{16)}$, lower extremity trauma ${ }^{17}$, total knee arthroplasty ${ }^{18)}$, shoulder pain ${ }^{19,20)}$, and chronic low back pain ${ }^{21)}$. To optimize patient outcomes, physical therapists should integrate psychological principles into physical therapy sessions ${ }^{15}$. Power posing is a psychological approach that may have tremendous potential in physical therapy care.

The nature of the clinician-patient relationship can often influence patients in a way that naturally causes the patient to assume a low-power pose during a stressful physical therapy session. Because adopting such a low-power pose may negatively impact patients, incorporating high-power posing for patients into their physical therapy intervention could potentially be useful in reversing those negative effects and improving patient outcomes. It was found that adopting a high-power pose can increase pain tolerance as measured by the tourniquet technique, which involves using a blood pressure cuff to reduce blood flow to the participant's arm and inducing pain ${ }^{22}$. The same study also showed that interacting with individuals adopting a high-power pose can decrease pain thresholds and grip strength ${ }^{22}$. However, the postural interventions used in the study include standing and sitting which may alter the blood flow to the arm and confound the pain threshold tolerance measurements using the tourniquet technique. In addition, recent experiments based on a larger sample size failed to confirm the effects of high-power poses on hormonal level and risk tolerance ${ }^{23)}$. To our knowledge, there is a lack of rigorous research regarding the implications of high-power posing on patient outcomes in physical therapy.

We were interested in integrating high-power posing in physical therapy sessions to improve outcomes. Muscle strength and pain threshold are representative outcome measurements routinely used in physical therapy sessions and therefore chosen as outcome measurements. The purpose of this study was to determine the effects of high-power posing on muscle strength and pain threshold. The significance of this research project is that it may provide insight regarding physical therapy interventions for posture and enhance patient outcomes in physical therapy.

\section{SUBJECTS AND METHODS}

Thirty-one subjects, 16 females and 15 males, mean age 28.9 (SD 10.8) years old, were recruited through a convenience sampling on a university campus by email and word of mouth. The inclusion criteria included male or female, age 18 to 65 , with all four extremities intact without amputation, and the ability to stand still for 3 minutes. The exclusion criteria included inability to stand with their feet together or one foot apart for at least 3 minutes, inability to wrap their arms around their torso or keep their hands on their hips for 3 minutes, inability to squeeze their dominant hand into a fist, lack of sensation in the region surrounding the upper trapezius muscle, and cognitive impairments that interfere with the experimental procedures. Ethics approval for this study was sought and obtained from the Institutional Review Board at Youngstown State University (Protocol number 145-16). Written informed consent was obtained from each subject. Body weight and height for each subject were not collected.

The research design was a randomized controlled trial. Subjects were randomly assigned to the experimental group or the control group using a shuffled deck of cards. Subjects were instructed to randomly pick a card. The color (red or black) of the card represented the group allocation (experimental or control). The outcome measurements were conducted before and after the postural intervention.

In the experimental group, the subjects were instructed to stand in a high-power posture with hands on their hips, elbows pointing out and feet approximately one foot apart for 3 minutes (Fig. 1). In the control group, the subjects were instructed to stand in a low-power posture with hands and arms wrapping around the torso and feet together for 3 minutes (Fig. 2).

Outcome measurements included grip strength in the dominant hand and pain threshold in the upper trapezius muscle on the non-dominant hand side. Grip strength was measured using an electronic hand dynamometer (model EH 101, Camry Scale, City Industry, CA, USA). The maximal contraction measurements of grip strength have excellent test-retest reliability and validity ${ }^{24,25)}$ and hence were used in the study. Pain threshold was measured using a digital manual muscle dynamometer (model Micro FET 2, Hoggan Scientific, LLC, Salt Lake City, UT, USA). The subjects were instructed to report to the investigator when they began to feel pain or discomfort while the investigator gradually increased the force pushing on the center of upper trapezius muscle through the dynamometer. A familiarization trial was conducted for the pain threshold for each subject. The outcome measurements were conducted 3 times prior to the postural intervention to establish a baseline and 3 times immediately after the postural intervention to detect any changes.

Changes in grip strength and pain threshold are reported as means and 95\% confidence intervals (lower, upper 95\% confidence interval). For grip strength, the highest of the three trials was used for pre- and post-postural intervention grip strength. The change in grip strength was normalized by the pre-postural intervention strength. For pain threshold, the lowest of the three trials was used for pre- and post-postural intervention pain threshold. The change of the pain threshold was normalized 


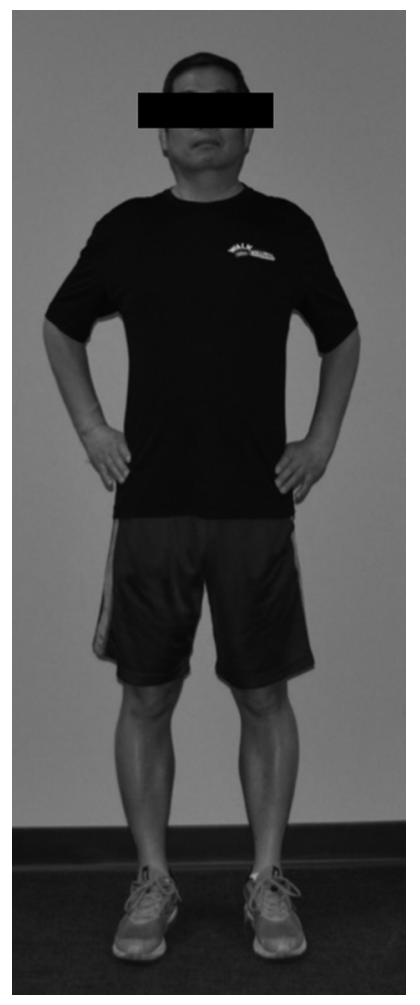

Fig. 1. The high-power pose adopted by subjects in the experimental group

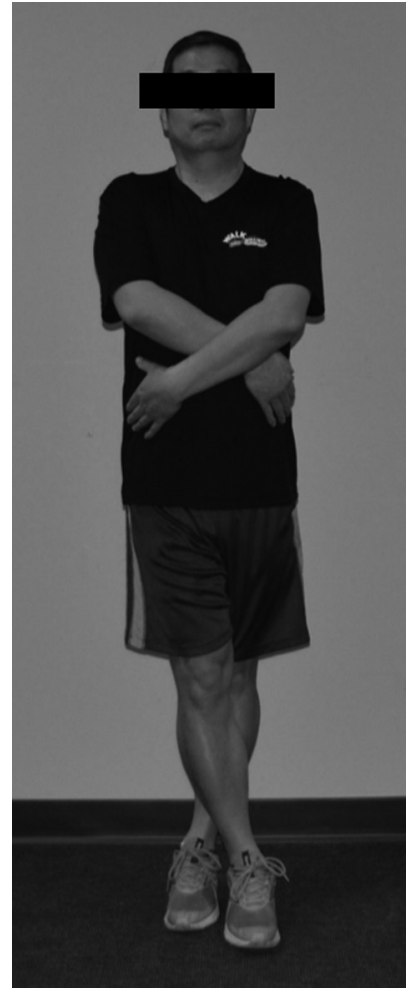

Fig. 2. The low-power pose adopted by subjects in the control group

Table 1. Comparisons of grip strength and pain threshold changes between the experimental and control groups (mean [lower, upper $95 \%$ confidence interval])

\begin{tabular}{lcc}
\hline Outcome & \multicolumn{2}{c}{ Group } \\
\cline { 2 - 3 } Measure & Experimental & Control \\
\hline Grip strength $(\%)$ & $-3.4(-3.7,0.3)$ & $1.7(-3.6,5.3) *$ \\
Pain threshold $(\%)$ & $0.6(-9.9,10.4)$ & $15.1(-9.3,24.4) *$ \\
\hline$* \mathrm{p}<0.05$ & &
\end{tabular}

by the pre-postural intervention pain threshold. Student t-tests were used to determine whether there were statistically significant differences between the changes of the outcome measurements in the experimental and control groups. An alpha value of 0.05 was used to determine statistical significance. Microsoft Excel for Mac version 15.25 was used for the data analysis.

\section{RESULTS}

Thirty-one subjects, 16 females and 15 males, mean age 28.9 (SD 10.8) years old, were recruited. The experimental group included 16 subjects ( 7 females and 9 males), mean age 30.8 (SD 12.5) years old. The control group included 15 subjects (9 females and 6 males), mean age 26.9 (SD 8.6) years old.

The grip strength changed by $-3.4(-3.7,0.3) \%$ and $1.7(-3.6,5.3) \%$ for the experimental and control groups, respectively. There was a statistically significant difference between the two groups $(\mathrm{p}=0.03)$. The pain threshold changed by 0.6 $(-9.9,10.4) \%$ and $15.1(-9.3,24.4) \%$ for the experimental and control groups, respectively. Again, there was a statistically significant difference between the two groups $(\mathrm{p}=0.02)$. However, both changes were not significant as all the $95 \%$ CIs included 0 . The results are summarized in Table 1. 


\section{DISCUSSION}

The data did not show significant benefits of high-power posing in increasing grip strength and pain threshold compared to low-power posing. We were not able to repeat the experiment results by Bohns on the benefits of high-power posing on pain threshold ${ }^{22}$. It is possible that this is because there are differences in the postural intervention and pain threshold measurement between the research projects. In the experiments by Bohns, three yoga poses were adapted as high-power, low-power, and control groups, respectively. The duration of the postural intervention was 20 seconds. To measure pain threshold, they used the tourniquet technique which induces pain by blocking blood flow to the arm with a blood pressure cuff. Part of the rationale for conducting the current research differently was that the postural interventions used in this study by Bohns included standing and sitting, which can create differences in blood pooling and alter blood flow to the arms, thus potentially confounding the pain threshold tolerance measurements using the tourniquet technique. In addition, different arm levels (one group had arms raised to shoulder level while the other two groups had arms kept at the body side) may also alter the blood flow to the arms. Further, the tourniquet technique in the experiments by Bohns may have been primarily stimulating the nociceptors found in arterial walls, which are different from the nociceptors found in the muscles and skin stimulated in our experiments. This may indicate that power posing affects sensory neurons in the autonomic system, which are located in arterial walls, differently than those in the somatosensory system, which are located in muscles and skin. Lastly, we adopted a 3-minute duration for postural interventions, which might be too long and cause discomfort to the subjects who may also feel awkward towards to the end of the 3 minutes, as Carney et al. speculated ${ }^{26)}$.

Different durations have been used in the research conducted by other researchers, ranging from as short as 20 seconds ${ }^{22}$ ) to one minute ${ }^{8)}$ to 5-6 minutes ${ }^{9}$. It is possible that "less is more" for the duration of postural interventions, but there is no data on the optimal duration available. Future rigorous research with a larger sample size from physical therapy clients on the optimal duration of power posing for maximal effects is necessary.

The limitations of the research project include convenience sampling and the small sample size limited by our available resources. Convenience sampling significantly impacts the generalizability of the results. The subjects were all young, healthy volunteers, and the sample lacks diversity. In addition, it was not possible to blind the participants to minimize subject and investigator bias.

Physical therapists routinely address posture issues in patients. While the results of this study were negative, we advocate that high-power posing be integrated in physical therapy. It is non-invasive and does not require additional equipment and space. It can be easily integrated into current therapeutic exercise programs and home exercise programs. It is beneficial to apply knowledge from psychology into physical therapy intervention to improve patient confidence at the very least. In addition, the optimal posture a physical therapist should adopt during clinician-patient interaction to improve the outcomes of patients with diversified cultural background should also be studied.

\section{REFERENCES}

1) Griegel-Morris P, Larson K, Mueller-Klaus K, et al.: Incidence of common postural abnormalities in the cervical, shoulder, and thoracic regions and their association with pain in two age groups of healthy subjects. Phys Ther, 1992, 72: 425-431. [Medline]

2) Kebaetse M, McClure P, Pratt NA: Thoracic position effect on shoulder range of motion, strength, and three-dimensional scapular kinematics. Arch Phys Med Rehabil, 1999, 80: 945-950. [Medline] [CrossRef]

3) Dolan KJ, Green A: Lumbar spine reposition sense: the effect of a 'slouched' posture. Man Ther, 2006, 11: 202-207. [Medline] [CrossRef]

4) Lee JH: Effects of forward head posture on static and dynamic balance control. J Phys Ther Sci, 2016, 28: 274-277. [Medline] [CrossRef]

5) Han J, Park S, Kim Y, et al.: Effects of forward head posture on forced vital capacity and respiratory muscles activity. J Phys Ther Sci, 2016, 28: 128-131. [Medline] [CrossRef]

6) Barrett E, O'Keeffe M, O'Sullivan K, et al.: Is thoracic spine posture associated with shoulder pain, range of motion and function? A systematic review. Man Ther, 2016, 26: 38-46. [Medline] [CrossRef]

7) Cuddy A: Your body language shapes who you are [Video file], 2012: http://www.ted.com/talks/amy_cuddy_your_body_language_shapes_who_you_are (Accessed Dec. 24, 2016)

8) Carney DR, Cuddy AJ, Yap AJ: Power posing: brief nonverbal displays affect neuroendocrine levels and risk tolerance. Psychol Sci, 2010, 21: 1363-1368. [Medline] [CrossRef]

9) Cuddy AJ, Wilmuth CA, Yap AJ, et al.: Preparatory power posing affects nonverbal presence and job interview performance. J Appl Psychol, 2015, 100: 1286-1295. [Medline] [CrossRef]

10) Fischer J, Fischer P, Englich B, et al.: Empower my decisions: the effects of power gestures on confirmatory information processing. J Exp Soc Psychol, 2011, 47: 1146-1154. [CrossRef]

11) Vacharkulksemsuk T, Reit E, Khambatta P, et al.: Dominant, open nonverbal displays are attractive at zero-acquaintance. Proc Natl Acad Sci USA, 2016, 113: 4009-4014. [Medline] [CrossRef]

12) Torelli CJ, Shavitt S: The impact of power on information processing depends on cultural orientation. J Exp Soc Psychol, 2011, 47: 959-967. [Medline] [CrossRef]

13) Melzack R, Wall PD: Pain mechanisms: a new theory. Science, 1965, 150: 971-979. [Medline] [CrossRef] 
14) McGrath PA: Psychological aspects of pain perception. Arch Oral Biol, 1994, 39: 55S-62S. [Medline] [CrossRef]

15) Linton SJ, Shaw WS: Impact of psychological factors in the experience of pain. Phys Ther, 2011, 91: 700-711. [Medline] [CrossRef]

16) Wood RL, Maclean L, Pallister I: Psychological factors contributing to perceptions pain intensity after acute orthopaedic injury. Injury, 2011, 42: 1214-1218. [Medline] [CrossRef]

17) Archer KR, Abraham CM, Obremskey WT: Psychosocial factors predict pain and physical health after lower extremity trauma. Clin Orthop Relat Res, 2015, 473: 3519-3526. [Medline] [CrossRef]

18) Lindberg MF, Miaskowski C, Rustøen T, et al.: Preoperative pain, symptoms, and psychological factors related to higher acute pain trajectories during hospitalization for total knee arthroplasty. PLoS One, 2016, 11: e0161681. [Medline] [CrossRef]

19) Menendez ME, Baker DK, Oladeji LO, et al.: Psychological distress is associated with greater perceived disability and pain in patients presenting to a shoulder clinic. J Bone Joint Surg Am, 2015, 97: 1999-2003. [Medline] [CrossRef]

20) George SZ, Wu SS, Wallace MR, et al.: Biopsychosocial influence on shoulder pain: influence of genetic and psychological combinations on twelve-month postoperative pain and disability outcomes. Arthritis Care Res (Hoboken), 2016, 68: 1671-1680. [Medline] [CrossRef]

21) Allegri M, Montella S, Salici F, et al.: Mechanisms of low back pain: a guide for diagnosis and therapy. F1000 Res, 2016, 5: 5. [Medline] [CrossRef]

22) Bohns VK, Wiltermuth SS: It hurts when I do this (or you do that): posture and pain tolerance. J Exp Soc Psychol, 2012, 48: 341-345. [CrossRef]

23) Ranehill E, Dreber A, Johannesson M, et al.: Assessing the robustness of power posing: no effect on hormones and risk tolerance in a large sample of men and women. Psychol Sci, 2015, 26: 653-656. [Medline] [CrossRef]

24) Roberts HC, Denison HJ, Martin HJ, et al.: A review of the measurement of grip strength in clinical and epidemiological studies: towards a standardised approach. Age Ageing, 2011, 40: 423-429. [Medline] [CrossRef]

25) Reuter SE, Massy-Westropp N, Evans AM: Reliability and validity of indices of hand-grip strength and endurance. Aust Occup Ther J, 2011, 58: 82-87. [Medline] [CrossRef]

26) Carney DR, Cuddy AJ, Yap AJ: Review and summary of research on the embodied effects of expansive (vs. contractive) nonverbal displays. Psychol Sci, 2015, 26: 657-663. [Medline] [CrossRef] 